\title{
Status Quo Analysis of the Energy Management System Development in Shandong Province
}

\author{
Jingmin Wang ${ }^{1 \mathrm{a}}$, Xiaoting $\mathrm{Li}^{1 \mathrm{~b}}$, Xiaoming $\mathrm{Dou}^{1 \mathrm{c}}$ and Changlan $\mathrm{Liu}^{1 \mathrm{~d}}$ \\ ${ }^{1}$ School of Business Administration, Shandong University of Finance and Economic, Jinan, 250014, \\ P.R. China \\ aJingminw@163.com, blxt_ly@126.com, c18763808212@163.com, d15265576583@163.com
}

\begin{abstract}
Keywords: Energy Management System; status quo analysis; countermeasures; Shandong Province

Abstract: Energy management system (EnMS) is the key means of enterprise energy management. As one of the leading provinces in promoting the application and development of EnMS in China, Shandong Province released the first provincial EnMS Standard (DB37/T 1013-2008) in 2008 and had have 1045 enterprises operated with EnMS until the end of 2015. Although EnMS's application brought significant energy-saving for some enterprises in the past years, there're several issues requiring considerations. This paper is to discuss the deficiencies and obstacles through both the field research and questionnaire survey within Shandong Province, and put forward countermeasures for effective promotion of EnMS. The final suggestions are made from three co-related dimensions: government, enterprise and the third party organizations.
\end{abstract}

\section{Introduction}

The Energy Management System (EnMS) is an innovative energy management model for enterprises. It provides an optimization model of energy management for different kinds of industries ${ }^{[6]}$. It is the forth important system besides the quality management system, environmental management system and safety management system. The EnMS certification started at first in northern European countries, such as Denmark and Sweden. In 2008, the international standard ISO50001 was developed. Chinese experts began to engage in research work of EnMS standards since 2002. After 6 years, the first provincial standard was released by Shandong Province (named as the Energy Management System - The Request, DB37/T 1013-2008) in 2008. And this standard became the foundation to form the national standard "EnMS", which was issued later in 2009 and amended in 2012. In this view of fact, Shandong's effort gave impetus to the formation and development of EnMS of the nation.

\section{Analysis of the Status Quo of EnMS in Shandong Province}

This study took enterprises with EnMS certificate in Shandong as the research object and used the methods of field research and questionnaire investigation to analyze the operation status and problems in applying EnMS certificate. Field research was composed of two stages: pre-investigation and formal investigation. The results of the pre-investigation were assist for the analysis of field survey.

In the pre-investigation stage, we visited 3 enterprises and improved the research topic and questionnaire design. Then, we carried out formal research on 14 companies in Jinan (the provincial capital of Shandong, and with the majority of EnMS certified enterprises) and the surrounding cities. Therefore, there are totally 17 enterprises in pre-investigation and formal investigation.

Questionnaire survey was carried out to enrich the research data while conducting field research. This study integrated the experts' opinions from enterprises, government energy conservation departments, then formed six sets of questionnaires: for principal of government energy conservation departments and energy conservation monitoring agencies, senior manager of key energy-consuming enterprises, energy managers; certification agency for EnMS, consulting agency for EnMS and energy conservation services agency. The questionnaires were distributed through two channels: by emails through the energy conservation association and online through "energy-saving" We Chat platform. A 
total of 142 valid questionnaires were obtained, among which there were 38 from enterprises, 59 from energy managers, 5 from energy-saving service enterprises, 5 from the certification agency, 25 from the consulting agency, and 10 from government departments.

Construction Situation. The EnMS received great concern in the interviewed enterprises. All them have established EnMS and passed the EnMS certification or the assessment from government. Enterprises hired consulting agency in the early stages of the EnMS construction, and revised system documents combined with the company's own situation. Therefore, the EnMS documents we searched are either standardized or innovative. For example, a provincial transportation company found that the template for writing EnMS manual report and other documents could be suitable for heavy industry but not for transportation industry. So it formed the first EnMS documents in the transportation industry nation-wide, and its EnMS documents became the template in the transportation industry.

Questionnaire results also indicated that the construction of the EnMS was in good condition: 36 of the 38 enterprises have established EnMS, of which 55.26\% have been certified and $39.47 \%$ passed the evaluation. 32 companies hired consulting agency, which is roughly same as the field results.

Operation Situation. 13 of 18 enterprises' (76\%) EnMS have been effectively running, maintaining and improving. 10 of the enterprises (59\%) have realized the full participation. 7 of 11 evaluated enterprises (64\%) continued to follow the standard requirements to maintain the operation of the EnMS. 5 enterprises' EnMS has been integrated with other systems (quality, safety, health, etc.) to varying degrees. In questionnaire survey "your company's EnMS and previous energy conservation management work can be carried out in parallel without integration" scored 2.68. Which also confirms the results of the field survey to some extent.

Research result shows that enterprises passed the certification and evaluation performed well in the operation, that is to say the operation is not directly related to the selection of certification or evaluation. For example, one coal gangue thermoelectric plant which evaluated conforming performed better in the operation of EnMS. It integrated energy conservation work according to the system framework, optimized energy-saving assessment indicators and achieved monthly adjustment of energy performance parameters.

Cognitive Situation. $81.25 \%$ researched enterprises stated that EnMS is designed primarily to meet governmental requirements. This item scored 3.71 in the questionnaire survey. 56.25\% enterprises acknowledged that top managers appreciated EnMS, half managers approved EnMS contributed much in saving energy. Meanwhile, directors of energy management realized that energy-saving competent authorities and inspective agencies attached seriously importance to EnMS. They pointed out that EnMS is an important framework for energy management. It played a positive role in increasing the energy efficiency and reducing costs. There also are enterprises achieving to quantify and visualize the benefits of EnMS, thus promoting the effective operation of the enterprise EnMS. China National Heavy Duty Truck Group Jinan Heavy Truck Co., Ltd constructed EnMS in 2013, certificated in 2014. The group recognized that energy-saving through management is much more significant than techniques. The amount of consuming raw coal decreased from 60000 tons/year to 10000 tons/year, and the coal cinder carbon content in coal cinder decreased from $50 \%$ to $2 \%$.

The item "energy departments and the supervisory organizations value the construction of EnMS" scored 4.29. The item "it is extremely important for energy management to promote the construction of EnMS" scored 4.5. The item "EnMS had made a lot contributions to saving energies" scored 4.29. This item scored 4.3 in the investigation for government, 4.52 for consultancy and 4.8 for certification agency. Concluding that the motivation constructed EnMS exchanged from outside (the government) to inside, from pressure to impetus. Enterprises originally set up EnMS under the pressure of government. But more enterprises realized advantages of EnMS in energy-saving and benefit-enhancing. Then the endogenous power produced. It reflected the vital function governments made, and indicated that governments should continuously guide in the process of the EnMS promotion. For example, the item for key energy-using enterprises "the main motivation of 
generalization of EnMS in the 13th Five-year Plan is enterprises' endogenous motivation and attention from chief managers" scored 4.26, with more than $89 \%$ of respondents approved.

It is found that corporate executives generally consider chief managers played the most important role in the construction, maintenance and continuous improvement of EnMS. They argued that EnMS could get sufficient resources, be converted into assessment and incentives, and ensure the linkages among departments only when top managers lay too much stress on it. This idea was also confirmed in the questionnaire survey of enterprises. As to the main power for companies to construct and run EnMS, recognition by the managers helped to reduce energy consumption and improve efficiency. Namely, recognition by the management level had the highest score, as shown in the Table 1. Similar results were found in the survey of energy managers, with more than 90 percent of respondents believing high-level's recognition was the key. Even so, there are examples improved that the effort of the directors is more vital than the high-level's attention. For example, the power improving the construction of EnMS mainly came from middle-level managers in China National Heavy Duty Truck Group Jinan Heavy Truck Co., Ltd and Shandong Yongfeng Group Co., Ltd

Table1. The results of the main power of EnMS in the questionnaire survey of enterprises

\begin{tabular}{|c|c|}
\hline \multicolumn{1}{|c|}{ Items } & Average \\
\hline $\begin{array}{c}\text { The main motivation for company to implement the EnMS is the approval from } \\
\text { high-level. }\end{array}$ & 4.05 \\
\hline $\begin{array}{c}\text { The main motivation for company to implement the EnMS is the promotion by } \\
\text { organization. }\end{array}$ & 3.82 \\
\hline $\begin{array}{c}\text { The main motivation for company to implement the EnMS is continuous approval } \\
\text { from government, EnMS certification authorities and other relevant organizations. }\end{array}$ & 3.89 \\
\hline
\end{tabular}

More than 68 percent of enterprises' cognition about energy-saving management have no longer been managing energy leaking and wasting issues, and realized the importance of energy-saving management. At the same time, more than 56 percent of respondents pointed out that the companies they served focused mainly on technical energy-saving rather than management energy-saving. It can be concluded that, on the one hand, enterprises' awareness of energy conservation and energy management is gradually improving, which is conducive to the further EnMS promotion. On the other hand, the potential for construction and operation of EnMS is considerable.

\section{Deficiencies and Obstacles in Applying EnMS in Shandong Province}

Deficiencies. Despite results of field survey showed that the EnMS were highly valued by enterprises, there are still some obvious deficiencies as followed:

As to quantifying benefits EnMS brought, there is only one enterprise could measure them. Enterprises could only measure the amount of overall energy-saving rather than each means, considering there are several energy-saving measures they applied in addition to EnMS.

For the seven enterprises choosing to be authenticated, five of them pointed out that there was a lack of on-site inspection during the authentication. They said that the censorship just checked the completeness of relevant documents. And for five enterprises choosing to be evaluated, there is only one still to be authenticated after the evaluation. The others didn't run as required. Therefore, some enterprises' EnMS is not working well.

Some managers charging in energy management could not grasp the language of EnMS, and confused some key concepts, such as energy performance, energy objective and energy baseline. The reason possibly were as followed: the language of EnMS is difficult; the managers were not trained adequately; frequent labor turnover; workers who were investigated were new workers, who weren't familiar with situation of the companies' EnMS.

Although the consultancies helped industrial enterprises a lot at the beginning, they did little for other industries. The assistance consultancies offered mainly in the width and length. Width refers to 
the support for different industries, which underperformed. Two transportation companies investigated stated that the models consultancies offered had no practical value to them. Then they had to design models themselves according to their experience. Length referred to the time it took to provide advice and support, which was inadequate, too. For example, the clientage between enterprises and consultancies ended after the evaluation.

Obstacles. The main obstacles to deficiencies above are summarized as follows:

The language of EnMS is hard to understand and lack of publicity.The national and local standards of the EnMS are both based on international standards. Though localized, the language is still relatively obscure and indigestible. Before the EnMS introduced to enterprise, enterprise has formed a set of language and habits in energy management, which creates conflicts between traditional and new language system. Answers of item, theory of EnMS needs further innovation to be comprehensible, all got more than 4, which indicated that respondents generally approved that current EnMS language was indigestible.

On the basis of such obscure EnMS language, it would have influence on the promotion of EnMS if enterprises lack of advertising or encouraging employees to use it. In the field research, individual enterprises said that the consulting company personnel' explanation on EMS is dull, difficult understanding, and lack learning mechanism stimulation. And even one enterprise' energy management staff is not clear to the concept of "energy performance", which is directly related to the inadequacy of the system.

The performance evaluation method of EnMS is inadequate and the supporting standard is insufficient. Although enterprises researched is generally accepted the efficiency of EnMS, but the indicators measured efficiency is too little. From the government perspective, there is because no standard in the performance evaluation of the EnMS in China and inadequate supporting standards. From the enterprise perspective, the energy efficiency of EnMS can't be quantified rationally, which caused by the unscientific and incomplete energy performance parameters and energy standard, or the shallow energy assessment work, which is also related to the lack of professionals, or the limited liability of energy management teams in enterprises. In field survey found that the head of energy management in six enterprises are full-time, in 6 enterprises are at the top level, mostly are part-time, and their professional quality and ability need to be improved.

The government's support for EnMS is not enough to promote external pressure turn to internal forces. The government's implemented incentive mechanism is insufficient, which can't effectively promote the enterprise transfer external pressure into internal power to attract its enthusiasm. For example in pre-investigation questionnaire " The unfavorable factors of the EnMS implementation mainly are too few government support policies and smaller incentives" scored an average of 3.37. In a consulting company item, "The main factor that impedes the EnMS promotion is the lack of national policy support" scored an average of 3.52 .

Government supervision is not enough, continuous supervision and inspection is lacking. At present, the government's supervision is mainly in the construction stage, the regular supervision mechanism of the EnMS implementation is lacking, especially for the evaluated enterprises. It causes some enterprises which lacks internal power only focus on construction, not on operation; the system language and theory can't be implemented, only exist in the system documents. As mentioned above, in the field survey only one of the ten evaluated enterprises is in the internal force and continue to conduct external audit. From the perspective of government, certification body and consulting agency, $60 \%$ of the interviewee said that the current government supervision was insufficient.

The capacity of certification and consulting agency is inadequate, the service professionalism they providing remains to be strengthened. In field research, many companies said the service provided by consulting and certification agency is limited, they only provides file templates. Some enterprises modify the file according to their condition, but consulting agency can provide little professional support. Moreover, they only concern about the documents meeting the system requirements, do not pay attention to the actual energy situation of enterprise, only understand the system theory, but lack the specific operation situation of enterprises. 


\section{Suggestions for the Development of EnMS}

Based on the interview and questionnaire research, the suggestions for improving the development of EnMS could be discussed from three perspectives: government, enterprise and third party.

Government Level. Strengthen the guidance on the construction, improvement and operation of EnMS standards. Revise and improve EnMS standards. Gather experts from enterprises, certification and consulting agency to revise the teaching material, improve the system language, analysis the structure. Meanwhile, set up supporting standards, especially industry standards, to professionalize different industries. Encourage enterprises to communicate. Build learning platforms, publicize the latest laws and regulations regularly, introduce domestic and foreign advanced energy-saving experience, guide the communication among enterprises. Guide the consulting agency to improve professional guidance. Establish consultancy qualification review mechanism to find out the problems in the consultancy service timely to promote the service.

Strengthen the regulation of EnMS construction and operation. Establish the scientific EnMS application effect evaluation index and evaluation method. Improve the external audit mode, implement level certification through the application effect evaluation. Organize professional forces to review regularly, disqualify or reduce the level of qualification for enterprises without obvious effect. Improve the evaluation and certification quality of EnMS. Strictly Review the qualification of certification agency and standardize the certification behavior of enterprises. Establish a three-party linkage assessment mechanism for energy conservation department, energy enterprises and certification agency. Improve the quality of external inspection such as energy conservation supervision through standardize the external inspection reports, sampling review, etc.

Strengthen support for the construction and operation of EnMS. Strengthen the "gold content" of certification qualification of enterprise EnMS. Set up special identification of different qualification level, publicize outstanding enterprise cases to the society to promote its popularity. Improve the economic efficiency of certified enterprises, set up reward, give different preferential loans, priority approval of project and other support measures in accordance with the level of standards. Expand the scope of enterprises required for the construction of EnMS, encourage non-key energy-consuming enterprises to carry out EnMS.

Enterprise Level. Master the knowledge and implementation of EnMS. Select excellent staff to participate in knowledge training of EnMS, providing assistance for them such as create full-time training time by temporary adjustment of post work. Carry out EnMS knowledge training and discussion continuously in the enterprise. Hold the knowledge training meeting and lectures of EnMS on a regular basis by inviting professional staff to explain corresponding knowledge. And require all levels of managers and staff to participate in training sessions, assess the effectiveness of training.

Give full play to the role of professionals. Develop energy management professionals actively. Place employees with knowledge of the EnMS in the right position, give full authority to outstanding energy management professionals. Absorb experts' advice proactively, invite energy management experts to conduct on-site guidance.

Learn from the advanced experience of other enterprises actively. Allocate special responsibilities, require the energy management department to search for domestic and foreign advanced experience regularly, and pay close attention to new measures and experiences of other enterprises, especially for the same industry.

The Third Party. Certification agency of EnMS. Strive to improve the service level of self-certification. Cultivate and reserve comprehensive talents for the EnMS certification through recruitment, training, etc. to provide high-quality certification services. Implement the certification service specification strictly. Follow the standard of certification service strictly, strengthen the compliance awareness of certified service personnel to provide fair and standardized service.

Consulting agency of EnMS. Strive to improve the services level of consulting. Cultivate and reserve services personnel and energy management personnel through recruitment, training, etc. to 
provide high-quality system consulting services and energy-saving advisory services. Form a item-file system which to focus on energy enterprise to track service. That is, establish energy management file for each key energy-consuming enterprise, assign experts to provide one-to-one continuous service.

\section{Acknowledgements}

This work was financially supported by the Shandong Provincial Social Science Fund (14CGLJ13 ), Shandong High Education Social Science Research Fund(J14WF09) and the Energy Foundation.

\section{References}

[1] C. Walsh, P. Thornley: J.Clean. Prod., Vol.23 (2012), p.141

[2] Energy Access Action Plan: G20 energy ministerial meeting, Beijing, (2016)

[3] Lei Zhang, Xiong Huang: J. Nanjing Tech Un.(Social Science Edition), Vol.10(2011),pp.62(In Chinese)

[4] M. Rudberg, M. Waldemarsson and H. Lidestam: Applied Energy, Vol.104 (2013), p. 490

[5] Menghao Zhang, Jiaqi Liu: submitted to Economic Review (2015) (In Chinese)

[6] Xudong Zhao: Energy Management System, Standards Press of China, Beijing(2014), in press. (In Chinese)

[7] Z. Jerry, N. Gary: Strat. Plann. Energ. Environ., Vol. 32 (2013), p. 17 